\title{
Association between systemic lupus erythematosus and lung cancer: results from a pool of cohort studies and Mendelian randomization analysis
}

\author{
Haoxin Peng ${ }^{1,2 \#}$, Caichen $\mathrm{Li}^{1 \#}$, Xiangrong $\mathrm{Wu}^{1,2 \#}$, Yaokai Wen ${ }^{1,2 \#}$, Jinsheng Lin ${ }^{1,2}$, Hengrui Liang ${ }^{1}$, \\ Ran Zhong ${ }^{1}$, Jun Liu ${ }^{1}$, Jianxing He $^{1}$, Wenhua Liang ${ }^{1}$ \\ ${ }^{1}$ Department of Thoracic Oncology and Surgery, China State Key Laboratory of Respiratory Disease \& National Clinical Research Center for \\ Respiratory Disease, the First Affiliated Hospital of Guangzhou Medical University, Guangzhou, China; ${ }^{2}$ Nanshan School, Guangzhou Medical \\ University, Guangzhou, China \\ Contributions: (I) Conception and design: H Peng, C Li, X Wu, Y Wen; (II) Administrative support: H Peng, C Li, X Wu, Y Wen; (III) Provision \\ of study materials or patients: Y Wen, J Lin, H Liang, R Zhong; (IV) Collection and assembly of data: H Peng, X Wu; (V) Data analysis and \\ interpretation: H Peng, X Wu; (VI) Manuscript writing: All authors; (VII) Final approval of manuscript: All authors. \\ "These authors contributed equally to this work. \\ Correspondence to: Jianxing He, MD, PhD, FACS, FRCS, AATS active member, ESTS member; Wenhua Liang, MD. Department of Thoracic \\ Oncology and Surgery, the First Affiliated Hospital of Guangzhou Medical University, China State Key Laboratory of Respiratory Disease \& \\ National Clinical Research Center for Respiratory Disease, Guangzhou, China. Email: drjianxing.he@gmail.com; liangwh1987@163.com.
}

Background: Epidemiological evidence suggested that systemic lupus erythematosus (SLE) might be correlated with an increased risk of lung cancer. Nevertheless, few studies have comprehensively investigated their correlation and the causal effect remains unclear. With a meta-analysis and Mendelian randomization (MR) approach, we were able to systematically investigate the relationship between SLE and lung cancer risk.

Methods: A systematic search of cohort studies was conducted using network databases from the inception dates to February 1, 2020. Meta-analysis was performed to calculate standardized incidence rate (SIR) and their 95\% CI. Furthermore, utilizing 33 SLE-related single nucleotide polymorphisms as instrumental variables (IVs) identified by the latest genome-wide association studies (GWASs), we investigated the correlation between genetically predisposed SLE and lung cancer risk using summary statistics from the International Lung Cancer Consortium (11,348 cases and 15,861 controls). The Inverse variance-weighted method was applied to estimate the causality and we further evaluated the pleiotropy by means of the weighted median and the MR-Egger regression method. Subgroup analysis according to different histotypes of lung cancer was also conducted.

Results: Through meta-analysis of 15 cohort studies involving 110,519 patients, we observed an increased risk of lung cancer among SLE patients (SIR =1.63, 95\% CI, 1.39-1.90). Subgroup analysis suggested that female patients ( $\mathrm{SIR}=1.28,95 \% \mathrm{CI}, 1.13-1.44$ ) have a relatively higher lung cancer risk compared with male patients ( $\mathrm{SIR}=1.15,95 \% \mathrm{CI}, 1.02-1.30$ ). MR analysis indicated that genetically predisposed SLE was causally associated with an increased lung cancer risk ( $\mathrm{OR}=1.045,95 \% \mathrm{CI}, 1.005-1.086, \mathrm{P}=0.0276)$. When results were examined by histotypes, a causal relationship was observed between genetically predisposed SLE and squamous cell lung cancer (OR =1.065, 95\% CI, 1.002-1.132, P=0.0429). Additionally, the results demonstrated the absence of the horizontal pleiotropy.

Conclusions: Both meta-analysis and MR analysis results suggested that SLE was associated with an increased lung cancer risk. Further investigations are warranted to investigate the etiology underlying the attribution of SLE to lung cancer.

(C) Journal of Thoracic Disease. All rights reserved. 


\begin{abstract}
Keywords: Systemic lupus erythematosus (SLE); lung cancer risk; meta-analysis; Mendelian randomization (MR) analysis
\end{abstract}

Submitted Jul 17, 2020. Accepted for publication Sep 18, 2020.

doi: $10.21037 /$ jtd-20-2462

View this article at: http://dx.doi.org/10.21037/jtd-20-2462

\section{Introduction}

Systemic lupus erythematosus (SLE) is a systemic autoimmune disease which manifested as ischemic and dysfunctional tissue generation by means of production of autoantibody, activation of complement and immunecomplex deposition, thus chronic multiorgan inflammatory lesion is induced $(1,2)$. In terms of ethnicity, prevalence is highest among African Americans, followed by Asians and Hispanics (3); in regard to sex, SLE is more prevalent among women with ratios 9 times higher than men and is typically diagnosed during reproductive years $(4,5)$. Recent decades have seen remarkable improvement of survival in SLE patients on account of the progress of treatment, yet long-term complications such as secondary lung cancer have become the major issue of prognosis (6).

Considered as the major cause of cancer death, lung cancer remains the most commonly diagnosed cancer worldwide $(7,8)$. Previous studies have reported that SLE may play a role in the formation of pulmonary lesion via tissue fibrosis and vascular inflammation causing acute or chronic complications, e.g., interstitial lung disease (ILD) (9), thus potentially promoting the occurrence of lung cancer (10).

Previous epidemiological evidence concerning the correlation between SLE and lung cancer was inconsistent. A population-level cohort studies including 30,478 SLE patients in America reported a significantly increased risk of lung cancer among SLE patients (11). Likewise, a latest meta-analysis conducted in 2018 indicated that patients with SLE had a remarkably increased lung cancer risk of $62 \%$ (12). However, more recently, a nationwide populationbased study in Korea demonstrated no association between SLE and an increased risk of lung cancer (13). Previous observational studies have done a great job of selecting appropriate SLE patients since there are various classification criteria and meanwhile, the diagnosis remains challenging due to the heterogeneity of SLE (14). Some studies obtained valuable data of cigarette consumption and drug exposure like cyclophosphamide (CTX) among SLE patients $(15,16)$, which are beneficial to our better understanding of the potential roles of environmental and drug factors contributing to the pathogenesis of SLE. Notably, due to the nature of observational studies, these studies could be biased by confounders or reverse causation, making the current conclusions less accurate or invalid. Additionally, the causal effect between SLE and lung cancer remains unknown.

As a novel epidemiological genetic method, Mendelian randomization (MR), is designed to estimate the causality between risk factors and outcome of diseases, utilizing genetic variants as instrumental variables (IVs) by finding a genetic marker that satisfies IV assumptions. Singlenucleotide polymorphisms (SNPs) are used as the IVs, as their alleles are assigned to individuals before any exposure or outcome and thus, they are non-modifiable, ensuring lifelong exposure and reducing the occurrence of reverse causation and potential confounders (17). These genetic variants can be used as unconfounded proxies for modifiable risk factors because they are randomly assigned before birth and fixed at conception, similar to randomized controlled trials (RCTs) in an observational (non-experimental) setting. Nowadays, taking the advantage of the published summary data of recent discovered large-scale genomewide association studies (GWASs), in-depth study on the causal inferences on genetic aspects has become a feasible approach. Several chromosomes (18) had anteriorly found to reveal the hereditary relationship of the lung cancer risk. Also, in terms of SLE, genetic variants play a role in SLE occurrence, which has been confirmed since the heritability of SLE was estimated from $8.7 \%$ to $16.0 \%$ (19). Therefore, the MR analysis may offer a means to evaluate the causality between SLE and lung cancer.

Making attempt to investigate the correlation between SLE and risk of lung cancer, we first conducted a metaanalysis based on 15 population-level cohort studies (We present the following article in accordance with the PRISMA reporting checklist). Furthermore, utilizing 33 SLE-related SNPs as IVs identified by the latest GWASs, we investigated the correlation between genetically predisposed SLE and lung cancer risk using summary 
statistics from the International Lung Cancer Consortium (ILCCO, 11,348 cases and 15,861 controls). We also conducted additional MR analyses to investigate whether genetically predisposed SLE would be associated with common confounders and mediators of lung cancer risk based on existing literature, including obesity, alcohol consumption and smoking status (20). As far as we know, our study provided the latest evidence for assessing the causality between SLE and lung cancer through MR for the first time. We present the following article in accordance with the PRISMA reporting checklist (available at http://dx.doi.org/10.21037/jtd-20-2462).

\section{Methods}

\section{Meta-analysis}

\section{Academic retrieval strategies}

A systemic search was conducted using online databases, including Embase, Web of Science, Cochrane Library, PubMed and Web of Science, up to February 1, 2020. We used "systemic lupus erythematosus" or "lupus" or "SLE" combined with "lung cancer", "neoplasm" and "tumor" as well as their Medical Subject Headings (MeSH) terms. The references lists originating from retrieved review articles and conference abstracts were searched manually.

Studies regarding lung cancer risk among patients with SLE were included if they met the following criteria (21): (I) study design of population-level cohort studies of SLE patients, (II) sample size of patients more than 200, (III) data on lung cancer incidence obtained from official registers, (IV) studies provided relative risks (RRs), standardized incidence ratios (SIRs), odds ratios (ORs) or hazard ratios (HRs) with corresponding 95\% CIs of lung cancer among SLE patients and (V) studies with eligible follow-up time ( $>5$ years or $>1,000$ person-years). Studies were excluded if any of the following criteria was met: (I) case-control studies, cross-sectional studies or case report, (II) studies from referral centers and (III) studies not published in English, duplicate publications or conference abstracts without follow-up publication.

\section{Data extraction}

Three authors (H.P., W.X., Y.W.) extracted the available data independently and any divergences came to a unanimous decision after discussion among the 3 investigators. The name of the first author, sources of SLE patients, follow-up time (mean or median person-years or years), diagnosis of SLE, number of SLE patients (gender), number of lung cancer patients, SIRs with $95 \%$ CIs, country, study period and publication year of each study were recorded.

\section{Quality assessment}

Quality assessment was carried out based on Meta-analysis of Observational Studies in Epidemiology (MOOSE) (22) and Strengthening the Reporting of Observational Studies in Epidemiology (STROBE) (23) criteria based on a scale of 0-6 points, with 6 reflecting the best quality. One point was assigned for each of the following: (I) reasonable criteria of selected participants, (II) accurate SLE diagnosis based on American Rheumatology Academy (ARA), American College of Rheumatology (ACR) or European League Against Rheumatism (EULAR) classification criteria $(24,25)$, (III) descriptive data, such as the characteristics of participants and information of follow-up period, (IV) outcome data of lung cancer which was diagnosed in accordance with acknowledged clinical criteria (26), (V) adjusting for age and gender, (VI) other relevant adjustments such as smoking, race, past medical history and immunosuppressant therapy. Notably, if the SLE diagnosis was not precise or was not mentioned in the articles, the one would score 0 point on the project "Appropriate SLE diagnosis".

\section{Statistical analysis}

Given that the lung cancer risk is relatively low among SLE patients, we anticipated similar estimate in SIRs with HRs/ORs/RRs in accordance with Lin et al. described (27). Hence, study-specific SIRs with 95\%CIs for lung cancer were gathered to combine the data. Utilizing the $\mathrm{I}^{2}$ statistic and the Cochran's Q test, heterogeneity was evaluated. If an $\mathrm{I}^{2}$ statistic $\geq 50 \%$ then, the statistical heterogeneity was considered significant. A random-effects model was conducted if significant heterogeneity $\left(\mathrm{P}<0.5, \mathrm{I}^{2}>50 \%\right)$ was observed, otherwise a fixed-effects model was employed. Stratified analysis based on gender was carried out. Funnel plot tests, Egger's test and Begg's test were used to evaluate the publication bias. Sensitivity analysis was employed by omitting the studies singly. All the statistical manipulation was carried out using Stata software (version 15, StataCorp, TX, USA). Statistical significance was considered as $\mathrm{P}<0.05$. The PRISMA checklist for reporting systematic reviews and meta-analyses was used. Review protocol of this meta-analysis was registered in PROSPERO (ID CRD42020159082). 
Table 1 Details of International Lung and Cancer Consortium (ILCCO) included in Mendelian randomization analyses

\begin{tabular}{llllll}
\hline Trait & First author & Consortium & Number of cases & Number of controls & Sample size \\
\hline Lung cancer & Wang Y & ILCCO & 11,348 & 15,861 & 27,209 \\
Squamous cell lung cancer & Wang Y & ILCCO & 3,275 & 15,038 & 2014 \\
Lung adenocarcinoma & Wang Y & ILCCO & 3,422 & 14,894 & 2014 \\
\hline
\end{tabular}

ILCCO, the International Lung Cancer Consortium.

\section{Mendelian randomization}

\section{Data sources}

One hundred and six loci from 82 SNPs associated with SLE from 9 Genome-wide association studies (GWASs) published between 2008 and 2016 (19,28-35) (Table S1) were extracted from European ethnicity at the genome-wide significance threshold of $\mathrm{P}<5 \times 10^{-8}$. An exclusion was performed utilizing linkage disequilibrium (LD) analysis once mutual LD surpassed the limited value $\left(\mathrm{R}^{2}<0.001\right)$. Eventually, $33 \mathrm{SNPs}$ (Table S1) remained as the final genetic variants, explaining over $16 \%$ (19) of the heritability totally. Given the 27,209 individual sample size and 33 instrumental variants included in our study, the F-statistic was 5,183.67 (F>100) as estimated using the formulae from Burgess et al. (36), suggesting the instruments used strongly predicted SLE.

Our study included 11,348 lung cancer cases and 15,861 controls from ILCCO as epidemiological individual data (Table 1). In order to explore the possible association between SLE and specific cancer types, subgroup analysis was further conducted, including lung adenocarcinoma and squamous cell lung cancer.

\section{Power calculation}

Supposing the SNPs explain a total of $16 \%$ variance of SLE in accordance with previous estimates, our sample size of 11,348 cases of lung cancer and 15,861 controls had an approxiamted $100.0 \%$ power to detect the estimated causal effect size of SLE (SIR =1.66) previously (11) at a significance level of 0.05, based on the methods illustrated by Burgess (37). Alternatively, given our sample size, we also had $100 \%$ power to detect a minimal SIR of 1.30 (38) at a statistical significance level of 0.05 .

\section{Statistical analysis}

Several MR approaches were used to investigate MR estimates of SLE for lung cancer. We performed a random effects inverse variance-weighted (IVW) Waldtype estimator to derive a MR estimate of multiple IVs.
Given that the SNP effects on SLE cumulatively, the IVW estimate of the causal effect can be combined with the ratio estimate and standard error of a single SNP using the method of Burgess et al. (39). All previous hypotheses are assumed to be consistent with the previously described genetic variant $\mathrm{P}(\mathrm{P}=1 \ldots \mathrm{P})$; which is correlated with the mean change in SLE (Xp) of the risk factor observed with each other variant allele with standard error $(\sigma \mathrm{Xp})$ as well as observed (Yp) logarithmic change in the outcome of each allele with standard error $(\sigma \mathrm{Yp})$. The calculation is as follows:

$$
\hat{\beta}_{I V W}=\frac{\sum_{i=1}^{P} X_{p} Y_{p}{\sigma_{Y p}}^{-2}}{\sum_{i=1}^{P} X_{p}{ }^{2}{\sigma_{Y p}}^{-2}} ; \operatorname{se}\left(\hat{\beta}_{I V W}\right)=\sqrt{\frac{1}{\sum_{i=1}^{P} X_{p}{ }^{2}{\sigma_{Y p}}^{-2}}}
$$

Using $\hat{\beta}_{I V W}$ and se $\left(\hat{\beta}_{I V W}\right)$, we calculated corresponding ORs and $95 \%$ CIs.

\section{Sensitivity and pleiotropy analysis}

Three suppositions (40) establish the foundation for MR analysis: (I) the IVs are closely relevant to SLE; (II) the IVs of SLE affect lung cancer only in a straight-forward pathway omitting any other alternative pathways in causality; and (III) the genetic markers are independent with any other confounders. The first assumption was met since the SNPs in our final IV set were all below the genome-wide significance threshold $\left(\mathrm{P}=5 \times 10^{-8}\right)$. Leaveone-out analysis was performed, during which we omitted one SNP at a time sequentially and examined variation in causality and overall IVW estimation, to assess whether the estimation of MR analysis was biased or driven by a single SNP.

To verify the second hypothesis, weighted median method and MR-Egger regression were introduced as pleiotropy test by assessing the global pleiotropic effects. To assess whether the causal effect estimation of SLE on lung cancer was consistent across each individual SNP (41), Cochran's Q test was performed as heterogeneity test. The third assumption was examined to investigate the 
Table 2 Details of studies included in confounders and mediators of systemic lupus erythematosus

\begin{tabular}{llllll}
\hline Trait & First author & Consortium & Study participants & Year & Website \\
\hline Obesity class 1 (BMI: 30-34.9 kg/m²) & Berndt SI & GIANT & 98,697 & 2013 & http://giant.princeton.edu/ \\
Obesity class 2 (BMI: $35-39.9 \mathrm{~kg} / \mathrm{m}^{2}$ ) & Berndt SI & GIANT & 72,546 & 2013 & http://giant.princeton.edu/ \\
Obesity class 3 (BMI: $\left.\geq 40 \mathrm{~kg} / \mathrm{m}^{2}\right)$ & Berndt SI & GIANT & 50,364 & 2013 & http://giant.princeton.edu/ \\
Previous smoker & Neale & Neale Lab & 336,024 & 2017 & http://www.nealelab.is/uk-biobank \\
Current smoker & Neale & Neale Lab & 336,024 & 2017 & http://www.nealelab.is/uk-biobank \\
Alcohol consumption & Clarke & UK Biobank & 112,117 & 2017 & http://www.ukbiobank.ac.uk/ \\
\hline
\end{tabular}

GIANT, the Genetic Investigation of Anthropometric Traits.

potential confounding factors between the progress of SLE and lung cancer. Due to the fact that cigarette smoking, alcohol consumption as well as obesity are common factors affecting lung cancer incidence among SLE patients, we further performed additional MR analyses between confounders and the genetic variants of SLE (20). In detail, genetic effects on alcohol consumption status and smoking status were retrieved from Neale Lab, obesity levels were retrieved from The Genetic Investigation of Anthropometric Traits (GIANT) consortium (Table 2). Furthermore, we attempted to investigate whether the chosen SNPs for our study were also related to any confounders of both SLE and lung cancer indirectly by retrieving the previously published GWASs.

MR analysis was performed using the package TwoSampleMR (version 0.5.0) (42) in R (version 3.6.2).

\section{Results}

\section{Meta-analysis results}

\section{Search results and study characteristics}

Figure 1 demonstrated the flow diagram for searching and inclusion of studies with the ones excluded for reasons. At last, 15 population-based cohort studies were enrolled in our meta-analysis (Table 3). A total of 110,519 patients with SLE (89,963 females and 20,556 males) were represented. The follow-up period ranged from 1,000 person-years to 157,969 person-years or from 4.8 years to 32 years. In total, 1,615 lung cancer cases were reported (Table 3).

\section{Quality assessment}

The quality scores ranged from 4 to 6 points with 11 of the 15 studies (73\%) scored more than 5 points, highlighting the high quality. In terms of SLE diagnosis, 3 studies (20\%) utilized the ARA criteria (53), 8 studies (53\%) used ACR criteria (54) and the 4 remaining studies (25\%) did not mention which diagnostic criteria were used. 7 studies (44\%) had adjusted for other factors. Only 1 study met all criteria of the quality assessment tool (Table S2).

\section{Overall lung cancer risk in SLE}

A total of 15 population-level cohort studies concerning the analysis of SLE and lung cancer were carried out utilizing random-effects model on the basis of the low heterogeneity among studies $\left(\mathrm{I}^{2}=45.0 \%, \mathrm{P}=0.031\right.$, Cochran's $\mathrm{Q}$ test $=25.56)$. The findings demonstrated that SLE was correlated with an increased risk of lung cancer (SIR $=1.63,95 \%$ CI, 1.39-1.90). A forest plot of the SIRs is displayed in Figure 2.

Subgroup analysis concerning gender was employed with 6 studies which provided accessible data. Stratified analysis indicated that female patients (SIR $=1.28,95 \% \mathrm{CI}$, $1.13-1.44, \mathrm{I}^{2}=63.9 \%, \mathrm{P}=0.017$, Cochran's $\mathrm{Q}$ test $=14.70$ ) were related with the higher risk of lung cancer than male patients ( $\mathrm{SIR}=1.15,95 \%$ CI, 1.02-1.30, $\mathrm{I}^{2}=0.0 \%, \mathrm{P}=0.691$, Cochran's Q test $=3.23$ ) (Figure 2).

\section{Sensitivity analysis}

For sensitivity analysis, several studies were excluded which possessed the lowest score of qualification to assess the stability of our overall study. The results conclusively indicated a stabilization of the cohort studies we applied for the meta-analysis (Figure S1).

\section{Heterogeneity and publication bias}

The funnel-plot was not symmetric in appearance (Figure S2), indicating the existence of publication bias. Thus, meta regression was performed, which indicated that the divergence of sample size in different cohorts led to the original heterogeneity. Both Egger's test $(\mathrm{P}=0.379)$, Begg's 


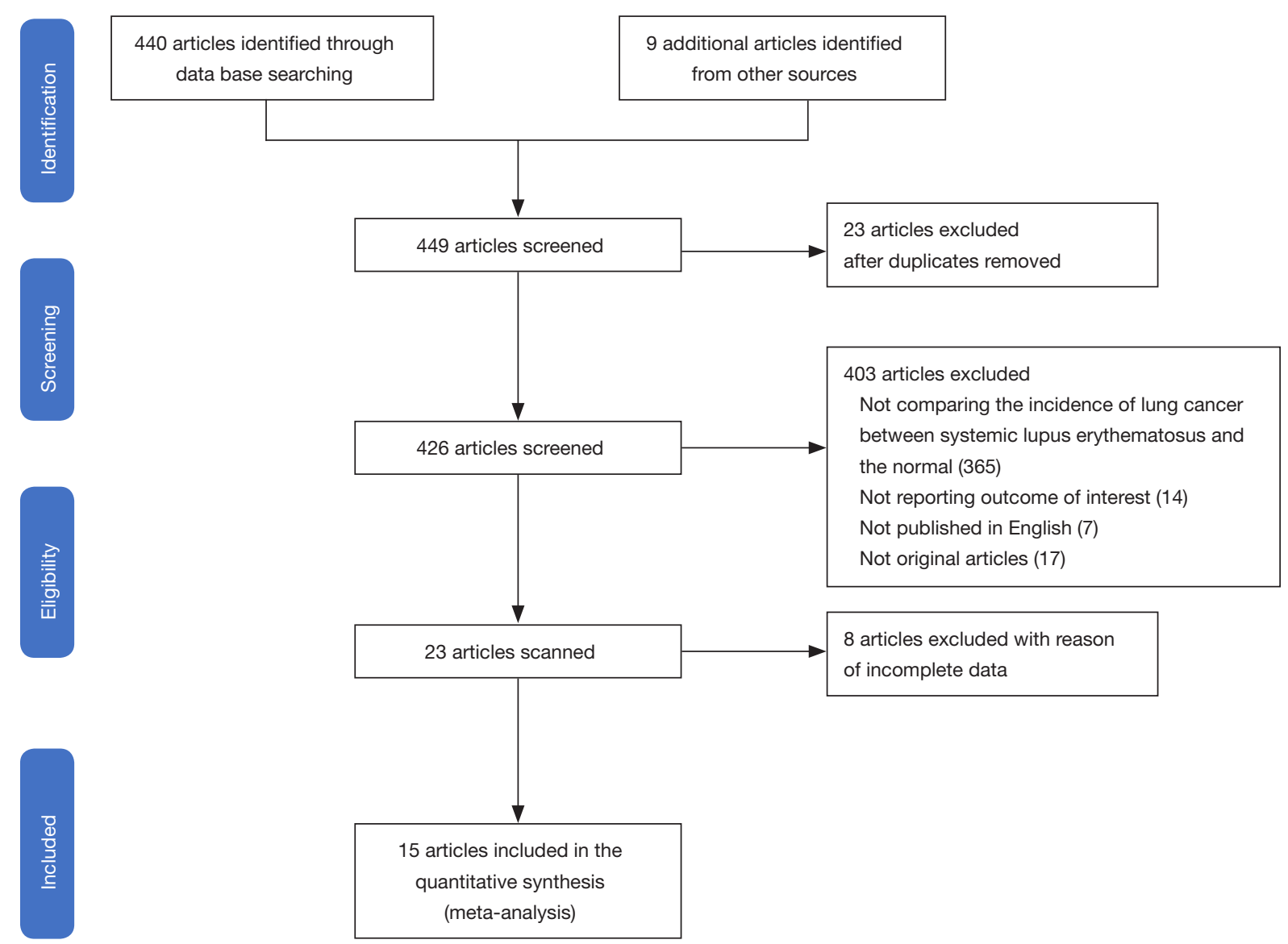

Figure 1 Flow diagram detailing the search strategy and identification of studies used in meta-analysis.

test $(\mathrm{P}=0.163)$ and Funnel plot test indicated no publication bias (Figures S3,S4).

\section{Mendelian randomization results}

\section{Individual SNP data}

Accessible summary statistics from the GWAS were adopted. 82 genetic variants from 106 loci were recognized as reaching genome-wide significance $\left(\mathrm{P}<5 \times 10^{-8}\right)$ in the consortium study, explaining $16 \%(19,28)$ of phenotypic variation in SLE. Eventually, 33 mutually uncorrelated variants were selected to carry out the IVs in the MR analysis. The details of the 82 SNPs enrolled in our study were represented in Table S1 and the Supplementary Data (available online: https://cdn. amegroups.cn/static/application/9a5e7d9ae8bd7b0db69e57a 4f55a4eec/JTD-20-2462-1.pdf).

\section{MR estimates for multi-polymorphism scores}

Being consistent with the findings in the meta-analysis, the conventional IVW method indicated a causal association between genetically predisposed SLE and overall lung cancer $(\mathrm{OR}=1.045,95 \% \mathrm{CI}, 1.005-1.086, \mathrm{P}=0.0276)$. Subgroup analysis demonstrated the existence of causality between genetically predisposed SLE and squamous cell lung cancer $(\mathrm{OR}=1.065,95 \% \mathrm{CI}, 1.002-1.132, \mathrm{P}=0.0429$ for IVW) as well (Table 4). Likewise, the MR-Egger and weighted median methods produced similar effect estimation, firmly indicating the result of the causation in our study (Table 4).

\section{Sensitivity analysis}

Leave-one-out analysis suggested that no single instrument was strongly driving the overall effect of SLE on lung cancer and squamous cell lung cancer, indicating that these results were not sensitive to SNP selection. (Figures $S 5, S 6$ ). No evidence was found for unbalanced pleiotropy among the IVs since MR-Egger regression had suggested (intercept $=-0.0120, \mathrm{P}=0.16$ for lung 
Table 3 Characteristics of the included studies in the meta-analysis

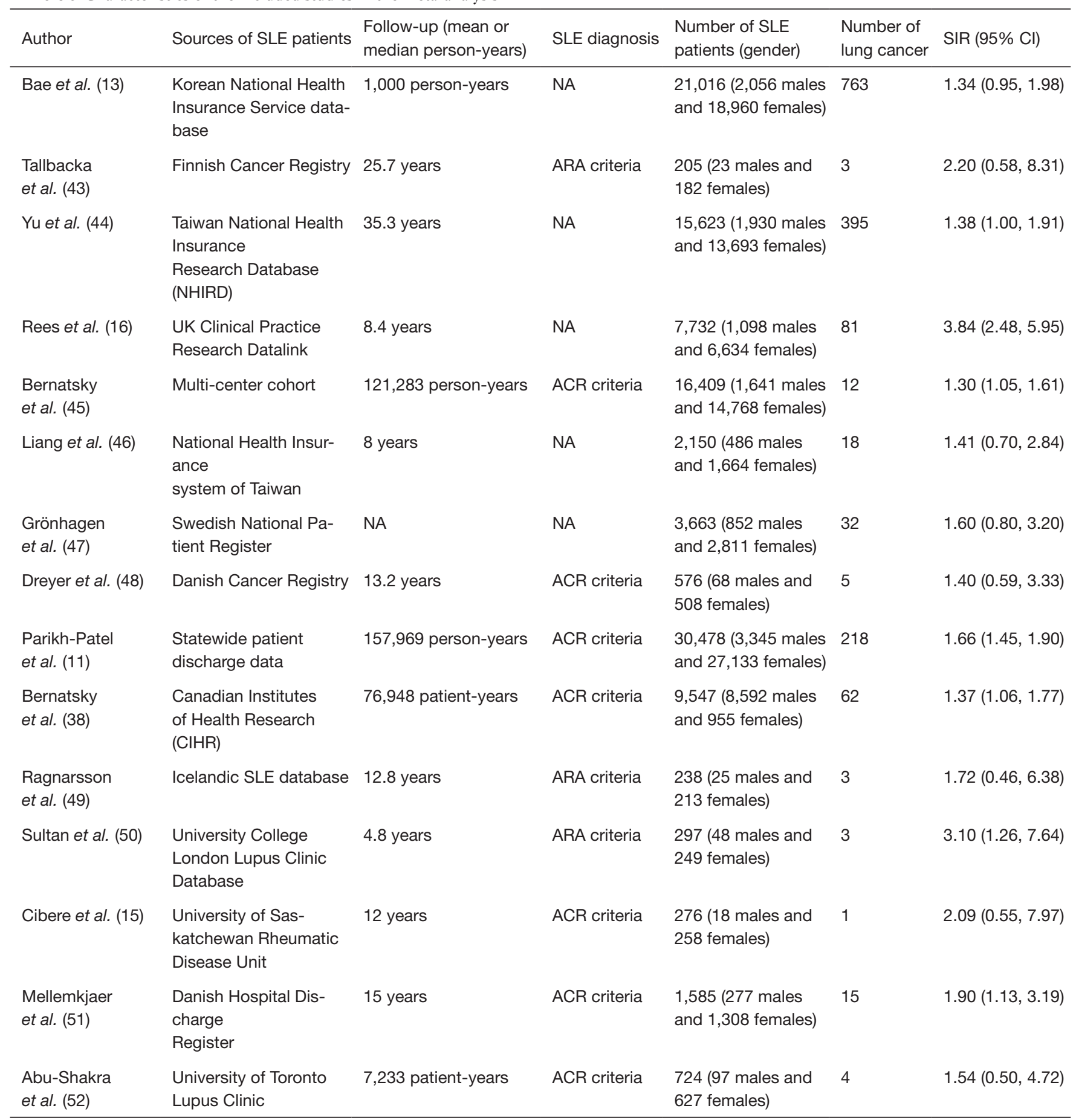

SLE, systemic lupus erythematosus; SIR, standardized incidence rate. 


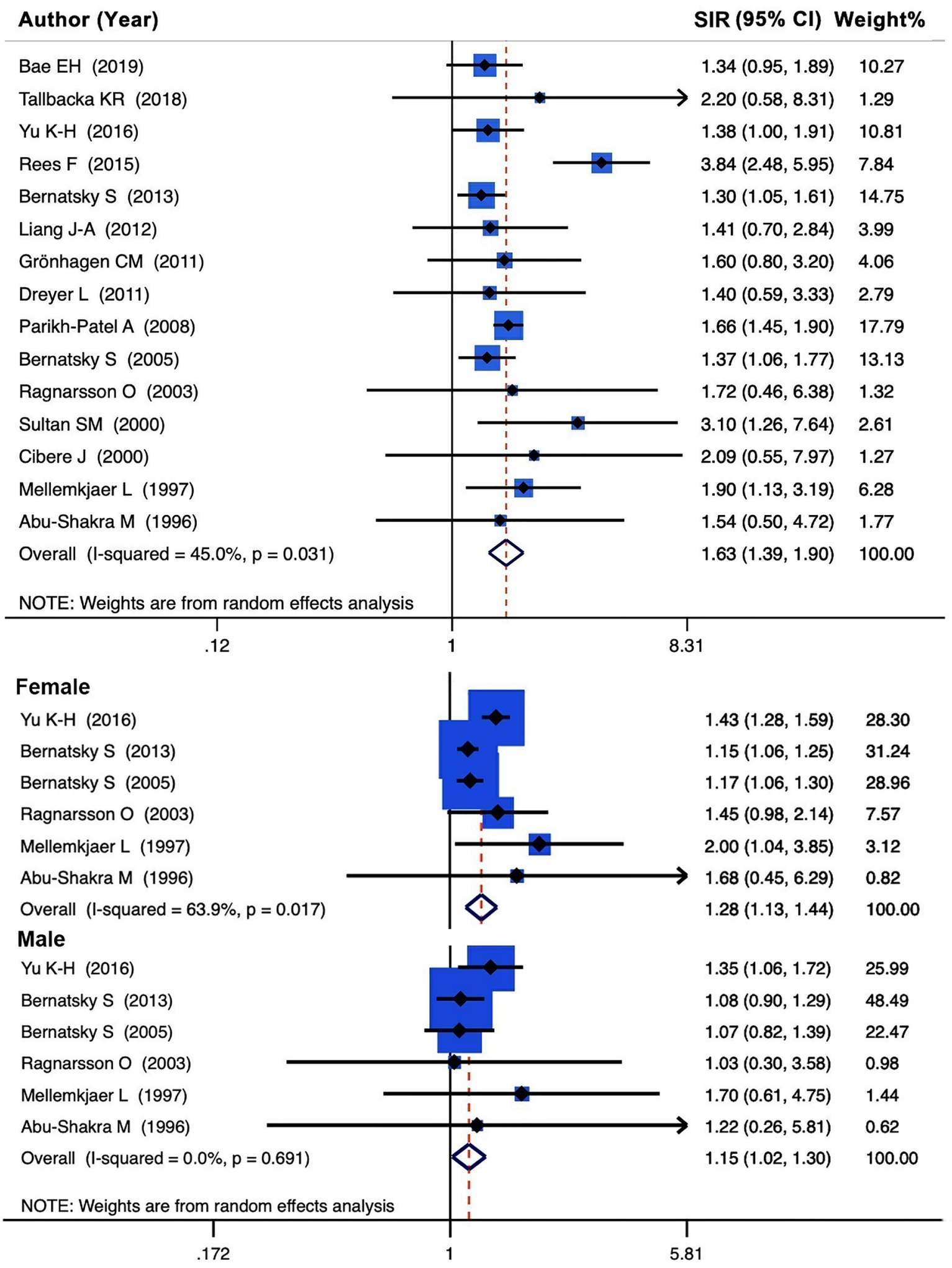

Figure 2 Comparing of lung cancer incidence in patients with or without systemic lupus erythematosus based on meta-analysis of populational-level cohort studies. 
Table 4 MR estimates of the causality between genetically predisposed systemic lupus erythematosus and lung cancer.

\begin{tabular}{|c|c|c|c|c|c|c|}
\hline Outcome & \multicolumn{2}{|c|}{ IVW method } & \multicolumn{2}{|c|}{ MR-Egger } & \multicolumn{2}{|c|}{ Weighted median method } \\
\hline Lung cancer overall & $1.045(1.005,1.086)$ & 0.0276 & $1.086(1.016,1.162)$ & 0.0236 & $1.039(0.993,1.088)$ & 0.0090 \\
\hline Squamous Cell Lung Cancer & $1.065(1.002,1.132)$ & 0.0429 & $1.128(1.015,1.254)$ & 0.0349 & $1.060(0.990,1.134)$ & 0.0939 \\
\hline Lung adenocarcinoma & $1.000(0.965,1.066)$ & 0.5825 & $1.055(0.966,1.151)$ & 0.2440 & $1.030(0.965,1.099)$ & 0.3735 \\
\hline
\end{tabular}

IVW, inverse variance-weighted; OR, odds ratio.

Table 5 Causal effects between genetically predisposed SLE and potential confounders and mediators.

\begin{tabular}{lcc}
\hline Outcomes & Causal effect $(95 \% \mathrm{Cl})$ & $\mathrm{P}$ value \\
\hline Obesity class 1 (BMI: $\left.30-34.9 \mathrm{~kg} / \mathrm{m}^{2}\right)$ & $1.005(0.982,1.029)$ & 0.6864 \\
Obesity class 2 (BMI: $\left.35-39.9 \mathrm{~kg} / \mathrm{m}^{2}\right)$ & $1.015(0.980,1.051)$ & 0.4046 \\
Obesity class 3 (BMI: $\left.\geq 40 \mathrm{~kg} / \mathrm{m}^{2}\right)$ & $1.078(1.005,1.155)$ & 0.0352 \\
Previous smoker & $0.999(0.996,1.002)$ & 0.5838 \\
Current smoker & $0.999(0.998,1.000)$ & 0.1314 \\
Alcohol consumption & $1.001(1.000,1.001)$ & 0.4594 \\
\hline
\end{tabular}

cancer; intercept $=-0.0210, \mathrm{P}=0.11$ for squamous cell lung cancer) (Table S3). Further, The IVW results we evaluated whether the correlation between SLE and lung cancer was influenced by obesity, smoking and alcohol consumption status demonstrated that genetically predisposed SLE were not causally associated with these potential confounders and mediators except obesity class 3 (BMI: $\geq 40 \mathrm{~kg} / \mathrm{m}^{2}$ ), the risk of which increased by $7.8 \%$ (OR $=1.078$, 95\% CI, $1.005-$ $1.155, \mathrm{P}=0.0352)$. Given that the results of epidemiological studies concerning the effects of obesity on lung cancer risk were conflicting $(55,56)$, the confounder (obesity) was unlikely to influence the SLE-lung cancer relation from our study (Table 5, Table S4). However, evidence in the published GWAS stated that a few SNPs associated with SLE in our study were associated with other systemic autoimmune diseases. Hence, caution is required in interpreting the outcomes.

The MR analysis therefore supported a causality between genetically predisposed SLE and lung cancer.

\section{Discussion}

As far as we know, our analysis comprehensively evaluated the relationship between SLE and lung cancer risk for the first time. Fifteen published population-level cohort studies, including 89,963 females and 20,556 males with SLE, were enrolled in the meta-analysis, the results of which suggested that SLE was correlated with an increased risk of lung cancer ( $\mathrm{SIR}=1.63,95 \% \mathrm{CI}, 1.39-1.90)$. Simultaneously, given that we only chose the populationbased cohort studies to conduct meta-analysis, it was reasonable to state that our study held a relatively stronger statistical power than previous meta-analyses combined both case-control studies and cross-sectional studies $(12,57)$. Moreover, stratified analysis suggested that female patients (SIR $=1.28,95 \% \mathrm{CI}, 1.13-1.44$ ) appeared to be more susceptible to lung cancer than male patients (SIR $=1.15,95 \%$ CI, 1.02-1.30).

Considering the shortcoming of observational studies that the causality cannot be inferred from the association between an exposure and an outcome, the association might be affected by reverse causality or confounders. Simultaneously, in view of the relatively long incubation period between SLE and the occurrence of lung cancer, it might be infeasible to investigate the causality through RCTs, which are widely accepted to answer questions of causality. From the point, our study can provide evidence by means of a novel type of study design, the two-sample MR, which also supported a positive association between SLE and risk of lung cancer. Several strengths of our study are as follow. First, to the very best of our knowledge, it is the largest study to investigate the causality between SLE and lung cancer risk using genetic variants. With large sample sizes $(n=27,209)$ and robustly associated IVs (F-statistics 
$=5,183.67$ ), our MR study with adequate statistical power could offer a relatively precise estimation of causal effect. Second, since once SLE-associated SNPs included in our study were also correlated with confounding factors, an accurate estimation of the causality between SLE and lung cancer would not be provided. Thus, we conducted additional MR analyses which indicated that genetically predisposed SLE was not causally associated with the potential confounders, including obesity, smoking and alcohol consumption, suggesting a relatively independent association between SLE and lung cancer. In addition, we stratified our outcomes according to histotypes, which was usually ignored by previous observational studies, further revealing a positive association between genetically predisposed SLE and squamous cell lung cancer.

Possible mechanisms have been proposed to explain the positive association between SLE and lung cancer risk. The Toll-like receptors (TLRs) are patternrecognition receptors which play an important role in innate immunity, but inappropriate TLR responses could contribute to the pathogenesis of autoimmune diseases, including SLE, rheumatoid arthritis, systemic sclerosis and so on (58). Previous study has demonstrated that the type I interferon pathway mediated by TLRs is important in the pathogenesis of SLE, with high IFN- $\alpha$ levels and increased expression of interferon-inducible genes (59). Consequently, inappropriate TLR responses in SLE may be the key inducers of the whole inflammatory cascade (60). The activated inflammation ultimately results in a release of inflammatory mediators into the extracellular environment, with subsequent activation of innate immune cells (61). Furthermore, the chronic inflammation has been reported to be one of the most important pathogeneses of ILD among SLE patients (62). And the chronic inflammation in ILD could lead to extensive DNA damage, which is believed to be the underlying mechanism of the increased incidence of lung cancer $(63,64)$. The chronic inflammation may also promote the carcinogenesis of lung by the production of nitrogen species and reactive oxygen, the proliferation of cells and increase in angiogenesis during tissue repair, and the up-regulation of antiapoptotic genes through the

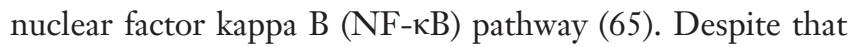
parenchymal involvement in SLE is commonly considered to be relatively infrequent, some SLE patients, especially those with longstanding disease, may be more susceptible to developing chronic fibrotic lupus pneumonitis and the incidence of lung cancer might increase consequently (66).
In addition, regarded as the independent risk factor for lung cancer, cigarette smoking has also been verified for the association with active SLE (67). Also, known as the main treatment for SLE patients, immunosuppressive drugs such as CTX and glucocorticoid which suppress immune surveillance by facilitating the survival and proliferation of abnormal cells have been reported to be related with its carcinogenic potential (68). Regarded as the first-line treatment for ILD and progressive skin-related diseases through inhibiting the progression of fibrosis, CTX makes a significant difference in the progression of malignancy because of the cellular injury during the process. Meanwhile, CTX has been reported to potentially increase the risk of bladder cancer (69). Use of mycophenolate is also an important facilitation of the cancerization (70). Nevertheless, related studies regarding carcinogenic effect of immunosuppressive drugs on lung cancer are rare and its mechanism remains unclear. Overall, the exact etiology underlying the attribution of SLE to risk of lung cancer remains unclear and more studies are warranted to further investigate their interaction.

Both meta-analysis and MR analysis results revealed an association between SLE and increased lung cancer risk. Further investigations with larger sample sizes and better designs are needed to verify our findings. Secondly, from the prospective of public health, discovering the etiology underlying the attribution of SLE to lung cancer is essential, which contributes to the long-term improvement of prognosis. Thirdly, early diagnosis of lung cancer among SLE patients is of vital importance, effective approaches including Low-dose CT (LDCT) screening (71), aspiration biopsy, targeted DNA methylation sequencing of circulating tumor DNA (ctDNA) (72) are accessible. It is also worth noting that the absolute numbers of SLE patients who died from lung cancer are relatively small even though a positive association between the two diseases was presented in our study. In conclusion, further studies will allow patients with SLE to be advised and monitored accordingly.

There are several limitations to our study. First, the inconsistency or lack of SLE diagnosis in some of the included studies could be the source of heterogeneity. Secondly, due to the finite original data from populationlevel cohort studies, we were only able to employ subgroup analysis stratified by gender, thus the effects of other confounders like age, smoking status, career exposure and treatments could not be evaluated or clarified. Third, articles written in languages other than English were not 
included in this study, which might impede generalization of the conclusions.

Limitations of MR analysis exist. First, though we've used the most comprehensive set of genetic variants so far, it merely explained a part of variance of SLE across individuals. It is possible that some unknown SLE-related SNPs could also play an important role in the development of lung cancer. Second, all three MR assumptions could not be absolutely tested in our study and potential violations may occur. Due to the fact that the second assumption cannot be evaluated directly, additional sensitivity analyses were implemented in our study. No horizontal pleiotropic effects existed in our study, suggesting no violation of the second MR assumption. It is possible that some of the genetic variants were also associated with confounders of SLE and lung cancer in our study and caution is needed in considering the gross effect. Further, despite that 82 SLErelated SNPs were obtained from the published GWASs, a score including more SNPs up to date from other network database would have stronger power to detect a causal effect.

In summary, there is no doubt that the cancer prevention is the key to lowering the morbidity and mortality of cancers. Consequently, we ought to attach great importance to identifying more modifiable risk factors correlated with cancers. Afterwards, we are able to employ effective interventions to reduce the disease burden worldwide, especially in developing countries. Population-level cohort studies with more samples, appropriate and explicit SLE diagnostic criteria, better epidemiological design and suitable follow-up period are necessary. MR estimate constructed using genetic variants associated with different mechanisms, such as chronic inflammation and extensive DNA damage, may be beneficial in understanding the etiology of the occurrence and development of lung cancer among patients with SLE (73).

\section{Conclusions}

Consistent with the findings of the meta-analysis, MR results pointed to the existence of the causality. Both IVW, weighted median, and MR-Egger regression were employed to verify the reliability and accuracy of our findings, resulting in the authentic conclusions. Our results identified a causal risk factor for lung cancer which might contribute to long-term improvement of prognosis, including early-stage diagnosis of lung cancer and to take precautions against complications among SLE patients. From the prospective of public health, the etiology underlying the attribution of SLE to lung cancer warrants further investigation. Better designed population-level cohort studies and MR analysis using more genetic variants and individual-level samples are necessary to examine our findings and deeper our understanding of the two diseases.

\section{Acknowledgments}

The authors thank Ms. Lindsey Hamblin for helping to edit the manuscript. The authors acknowledge the efforts of the International Lung Cancer Consortium (ILCCO) in providing high quality GWAS data for researchers.

Funding: This work was supported by China National Science Foundation (Grant number 81871893); Key Project of Guangzhou Scientific Research Project (Grant number 201804020030). Cultivation of Guangdong College Students' Scientific and Technological Innovation ("Climbing Program" Special Funds) (Grant number pdjh2020a0480).

\section{Footnote}

Reporting Checklist: The authors have completed the PRISMA reporting checklist. Available at http://dx.doi. org/10.21037/jtd-20-2462

Peer Review File: Available at http://dx.doi.org/10.21037/jtd20-2462

Conflicts of Interest: All authors have completed the ICMJE uniform disclosure form (available at http://dx.doi. org/10.21037/jtd-20-2462). JX He serves as the unpaid Executive Editor-in-Chief of Journal of Thoracic Disease. WH Liang serves as an unpaid editorial board member of Journal of Thoracic Disease from Apr 2018 to Apr 2021. The other authors have no conflicts of interest to declare.

Ethical Statement: The authors are accountable for all aspects of the work in ensuring that questions related to the accuracy or integrity of any part of the work are appropriately investigated and resolved.

Open Access Statement: This is an Open Access article distributed in accordance with the Creative Commons Attribution-NonCommercial-NoDerivs 4.0 International License (CC BY-NC-ND 4.0), which permits the noncommercial replication and distribution of the article with the strict proviso that no changes or edits are made and the 
original work is properly cited (including links to both the formal publication through the relevant DOI and the license). See: https://creativecommons.org/licenses/by-nc-nd/4.0/.

\section{References}

1. Fava A, Petri M. Systemic lupus erythematosus: Diagnosis and clinical management. J Autoimmun 2019;96:1-13.

2. Yang $\mathrm{X}$, Wang $\mathrm{W}, \mathrm{Xu} \mathrm{J}$, et al. Significant association of CD4+CD25+Foxp3+ regulatory $\mathrm{T}$ cells with clinical findings in patients with systemic lupus erythematosus. Ann Transl Med 2019;7:93.

3. Stojan G, Petri M. Epidemiology of systemic lupus erythematosus: an update. Curr Opin Rheumatol 2018;30:144-50.

4. Ramirez GA. Genetics in systemic lupus erythematosus: entering the borough of cardiovascular risk. Ann Transl Med 2018;6:S14.

5. Nusbaum JS, Mirza I, Shum J, et al. Sex Differences in Systemic Lupus Erythematosus: Epidemiology, Clinical Considerations, and Disease Pathogenesis. Mayo Clin Proc 2020;95:384-94.

6. Trager J, Ward MM. Mortality and causes of death in systemic lupus erythematosus. Curr Opin Rheumatol 2001;13:345-51.

7. Siegel RL, Miller KD, Jemal A. Cancer statistics, 2020. CA Cancer J Clin 2020;70:7-30.

8. Sun M, Guo Y, Shao G, et al. Analysis of real-word mutations of lung cancer driver genes in five regions of China. Transl Cancer Res 2019;8:2581-92.

9. Harris JM, Johnston IDA, Rudd R, et al. Cryptogenic fibrosing alveolitis and lung cancer: the BTS study. Thorax 2010;65:70-6.

10. Naccache J-M, Gibiot Q, Monnet I, et al. Lung cancer and interstitial lung disease: a literature review. J Thorac Dis 2018;10:3829-44.

11. Parikh-Patel A, White RH, Allen M, et al. Cancer risk in a cohort of patients with systemic lupus erythematosus (SLE) in California. Cancer Causes Control 2008;19:887-94.

12. Song L, Wang Y, Zhang J, et al. The risks of cancer development in systemic lupus erythematosus (SLE) patients: a systematic review and meta-analysis. Arthritis Res Ther 2018;20:270.

13. Bae EH, Lim SY, Han KD, et al. Systemic lupus erythematosus is a risk factor for cancer: a nationwide population-based study in Korea. Lupus 2019;28:317-23.

14. Kaul A, Gordon C, Crow MK, et al. Systemic lupus erythematosus. Nat Rev Dis Primers 2016;2:16039.
15. Cibere J, Sibley J, Haga M. Systemic lupus erythematosus and the risk of malignancy. Lupus 2001;10:394-400.

16. Rees F, Doherty M, Grainge M, et al. Burden of Comorbidity in Systemic Lupus Erythematosus in the UK, 1999-2012. Arthritis Care Res (Hoboken) 2016;68:819-27.

17. Sekula P, Del Greco MF, Pattaro C, et al. Mendelian Randomization as an Approach to Assess Causality Using Observational Data. J Am Soc Nephrol 2016;27:3253-65.

18. Bin J, Bernatsky S, Gordon C, et al. Lung cancer in systemic lupus erythematosus. Lung cancer 2007;56:303-6.

19. Bentham J, Morris DL, Graham DSC, et al. Genetic association analyses implicate aberrant regulation of innate and adaptive immunity genes in the pathogenesis of systemic lupus erythematosus. Nat Genet 2015;47:1457-64.

20. Malhotra J, Malvezzi M, Negri E, et al. Risk factors for lung cancer worldwide. Eur Respir J 2016;48:889-902.

21. Stang A. Critical evaluation of the Newcastle-Ottawa scale for the assessment of the quality of nonrandomized studies in meta-analyses. Eur J Epidemiol 2010;25:603-5.

22. Stroup DF, Berlin JA, Morton SC, et al. Meta-analysis of observational studies in epidemiology: a proposal for reporting. Meta-analysis Of Observational Studies in Epidemiology (MOOSE) group. JAMA 2000;283:2008-12.

23. Lachat C, Hawwash D, Ocké MC, et al. Strengthening the Reporting of Observational Studies in EpidemiologyNutritional Epidemiology (STROBE-nut): An Extension of the STROBE Statement. PLoS Med 2016;13:e1002036.

24. Aringer M, Costenbader K, Daikh D, et al. 2019 European League Against Rheumatism/American College of Rheumatology classification criteria for systemic lupus erythematosus. Ann Rheum Dis 2019;78:1151-9.

25. Hochberg MC. Updating the American College of Rheumatology revised criteria for the classification of systemic lupus erythematosus. Arthritis Rheum 1997;40:1725.

26. Ettinger DS, Wood DE, Aisner DL, et al. Non-Small Cell Lung Cancer, Version 5.2017, NCCN Clinical Practice Guidelines in Oncology. J Natl Compr Canc Netw 2017;15:504-35.

27. Lin L, Chu H, Murad MH, et al. Empirical Comparison of Publication Bias Tests in Meta-Analysis. J Gen Intern Med 2018;33:1260-7.

28. Morris DL, Sheng Y, Zhang Y, et al. Genome-wide association meta-analysis in Chinese and European individuals identifies ten new loci associated with systemic lupus erythematosus. Nat Genet 2016;48:940-6.

29. Armstrong DL, Zidovetzki R, Alarcón-Riquelme ME, et 
al. GWAS identifies novel SLE susceptibility genes and explains the association of the HLA region. Genes Immun 2014;15:347-54.

30. Lee YH, Bae SC, Choi SJ, et al. Genome-wide pathway analysis of genome-wide association studies on systemic lupus erythematosus and rheumatoid arthritis. Mol Biol Rep 2012;39:10627-35.

31. Chung SA, Taylor KE, Graham RR, et al. Differential genetic associations for systemic lupus erythematosus based on anti-dsDNA autoantibody production. PLoS Genet 2011;7:e1001323.

32. Gateva V, Sandling JK, Hom G, et al. A large-scale replication study identifies TNIP1, PRDM1, JAZF1, UHRF1BP1 and IL10 as risk loci for systemic lupus erythematosus. Nat Genet 2009;41:1228-33.

33. Kozyrev SV, Abelson AK, Wojcik J, et al. Functional variants in the B-cell gene BANK1 are associated with systemic lupus erythematosus. Nat Genet 2008;40:211-6.

34. Harley JB, Alarcón-Riquelme ME, Criswell LA, et al. Genome-wide association scan in women with systemic lupus erythematosus identifies susceptibility variants in ITGAM, PXK, KIAA1542 and other loci. Nat Genet 2008;40:204-10.

35. Hom G, Graham RR, Modrek B, et al. Association of systemic lupus erythematosus with C8orf13-BLK and ITGAM-ITGAX. N Engl J Med 2008;358:900-9.

36. Burgess S, Thompson SG. Avoiding bias from weak instruments in Mendelian randomization studies. Int $\mathrm{J}$ Epidemiol 2011;40:755-64.

37. Burgess S. Sample size and power calculations in Mendelian randomization with a single instrumental variable and a binary outcome. Int J Epidemiol 2014;43:922-9.

38. Bernatsky S, Boivin JF, Joseph L, et al. An international cohort study of cancer in systemic lupus erythematosus. Arthritis Rheum 2005;52:1481-90.

39. Burgess S, Butterworth A, Thompson SG. Mendelian randomization analysis with multiple genetic variants using summarized data. Genet Epidemiol 2013;37:658-65.

40. VanderWeele TJ, Tchetgen Tchetgen EJ, Cornelis M, et al. Methodological challenges in mendelian randomization. Epidemiology (Cambridge, Mass) 2014;25:427-35.

41. Emdin CA, Khera AV, Kathiresan S. Mendelian Randomization. JAMA 2017;318:1925-6.

42. Hemani G, Zheng J, Elsworth B, et al. The MR-Base platform supports systematic causal inference across the human phenome. Elife 2018;7:e34408.

43. Tallbacka KR, Pettersson T, Pukkala E. Increased incidence of cancer in systemic lupus erythematosus: a Finnish cohort study with more than 25 years of followup. Scand J Rheumatol 2018;47:461-4.

44. Yu KH, Kuo CF, Huang LH, et al. Cancer Risk in Patients With Inflammatory Systemic Autoimmune Rheumatic Diseases: A Nationwide Population-Based Dynamic Cohort Study in Taiwan. Medicine 2016;95:e3540.

45. Bernatsky S, Ramsey-Goldman R, Labrecque J, et al. Cancer risk in systemic lupus: an updated international multi-centre cohort study. J Autoimmun 2013;42:130-5.

46. Liang JA, Sun LM, Yeh JJ, et al. Malignancies associated with systemic lupus erythematosus in Taiwan: a nationwide population-based cohort study. Rheumatol Int 2012;32:773-8

47. Grönhagen CM, Fored CM, Granath F, et al. Increased risk of cancer among 3663 patients with cutaneous lupus erythematosus: a Swedish nationwide cohort study. Br J Dermatol 2012;166:1053-9.

48. Dreyer L, Faurschou M, Mogensen M, et al. High incidence of potentially virus-induced malignancies in systemic lupus erythematosus: a long-term followup study in a Danish cohort. Arthritis Rheum 2011;63:3032-7.

49. Ragnarsson O, Gröndal G, Steinsson K. Risk of malignancy in an unselected cohort of Icelandic patients with systemic lupus erythematosus. Lupus 2003;12:687-91.

50. Sultan SM, Ioannou Y, Isenberg DA. Is there an association of malignancy with systemic lupus erythematosus? An analysis of 276 patients under long-term review. Rheumatology 2000;39:1147-52.

51. Mellemkjaer L, Andersen V, Linet MS, et al. NonHodgkin's lymphoma and other cancers among a cohort of patients with systemic lupus erythematosus. Arthritis Rheum 1997;40:761-8.

52. Abu-Shakra M, Gladman DD, Urowitz MB. Malignancy in systemic lupus erythematosus. Arthritis Rheum 1996;39:1050-4.

53. Hopkinson ND, Doherty M, Powell RJ. Clinical features and race-specific incidence/prevalence rates of systemic lupus erythematosus in a geographically complete cohort of patients. Ann Rheum Dis 1994;53:675-80.

54. Yu C, Gershwin ME, Chang C. Diagnostic criteria for systemic lupus erythematosus: a critical review. J Autoimmun 2014;48-49:10-3.

55. Bhaskaran K, Douglas I, Forbes H, et al. Body-mass index and risk of 22 specific cancers: a population-based cohort study of 5•24 million UK adults. Lancet 2014;384:755-65.

56. Benn M, Tybjærg-Hansen A, Smith GD, et al. High body mass index and cancer risk-a Mendelian randomisation 
study. Eur J Epidemiol 2016;31:879-92.

57. Ni J, Qiu LJ, Hu LF, et al. Lung, liver, prostate, bladder malignancies risk in systemic lupus erythematosus: evidence from a meta-analysis. Lupus 2014;23:284-92.

58. Souyris M, Mejía JE, Chaumeil J, et al. Female predisposition to TLR7-driven autoimmunity: gene dosage and the escape from $\mathrm{X}$ chromosome inactivation. Semin Immunopathol 2019;41:153-64.

59. Kirou KA, Lee C, George S, et al. Activation of the interferon-alpha pathway identifies a subgroup of systemic lupus erythematosus patients with distinct serologic features and active disease. Arthritis Rheum 2005;52:1491-503.

60. Souyris M, Cenac C, Azar P, et al. TLR7 escapes X chromosome inactivation in immune cells. Sci Immunol 2018;3:eaap8855.

61. Berghöfer B, Frommer T, Haley G, et al. TLR7 ligands induce higher IFN-alpha production in females. J Immunol 2006;177:2088-96.

62. Fischer A, du Bois R. Interstitial lung disease in connective tissue disorders. Lancet 2012;380:689-98.

63. Hubbard R, Venn A, Lewis S, et al. Lung cancer and cryptogenic fibrosing alveolitis. A population-based cohort study. Am J Respir Crit Care Med 2000;161:5-8.

64. Yoon JH, Nouraie M, Chen X, et al. Characteristics of lung cancer among patients with idiopathic pulmonary fibrosis and interstitial lung disease - analysis of institutional and population data. Respir Res 2018;19:195.

65. Ballaz S, Mulshine JL. The potential contributions of chronic inflammation to lung carcinogenesis. Clin lung

Cite this article as: Peng $\mathrm{H}, \mathrm{Li} \mathrm{C}, \mathrm{Wu} \mathrm{X}$, Wen Y, Lin J, Liang H, Zhong R, Liu J, He J, Liang W. Association between systemic lupus erythematosus and lung cancer: results from a pool of cohort studies and Mendelian randomization analysis. J Thorac Dis 2020;12(10):5299-5312. doi: 10.21037/jtd-20-2462 cancer 2003;5:46-62.

66. Weinrib L, Sharma OP, Quismorio FP. A long-term study of interstitial lung disease in systemic lupus erythematosus. Semin Arthritis Rheum 1990;20:48-56.

67. Bernatsky S, Ramsey-Goldman R, Petri M, et al. Smoking Is the Most Significant Modifiable Lung Cancer Risk Factor in Systemic Lupus Erythematosus. J Rheumatol 2018;45:393-6.

68. Drevet G, Duruisseaux M, Maury JM, et al. Lung cancer surgical treatment after solid organ transplantation: A single center 30-year experience. Lung Cancer 2020;139:55-9.

69. Talar-Williams C, Hijazi YM, Walther MM, et al. Cyclophosphamide-induced cystitis and bladder cancer in patients with Wegener granulomatosis. Ann Intern Med 1996;124:477-84.

70. Gulamhusein A, Pope JE. Squamous cell carcinomas in 2 patients with diffuse scleroderma treated with mycophenolate mofetil. J Rheumatol 2009;36:460-2.

71. Li C, Liang H, Zhong N, et al. Optimal Starting Age for Lung Cancer Screening With Low-Dose Computed Tomography: A Population Level Analysis. J Thorac Oncol 2019;14:e82-4.

72. Liang $W$, Zhao $Y$, Huang $W$, et al. Non-invasive diagnosis of early-stage lung cancer using high-throughput targeted DNA methylation sequencing of circulating tumor DNA (ctDNA). Theranostics 2019;9:2056-70.

73. Burgess S, Small DS, Thompson SG. A review of instrumental variable estimators for Mendelian randomization. Stat Methods Med Res 2017;26:2333-55. 
Supplementary

Table S1 Information of the SNPs enrolled in MR study

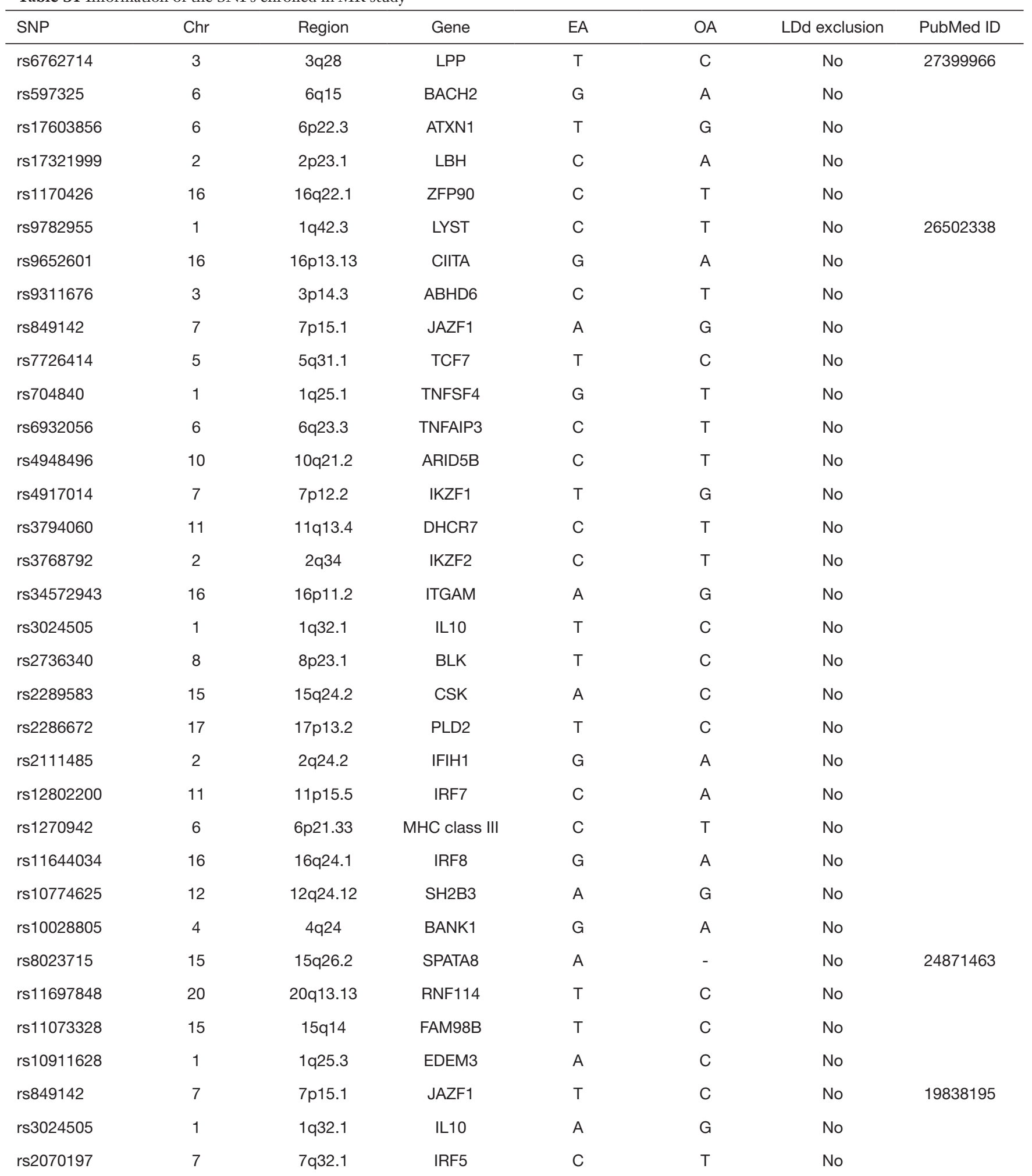

SNP, single-nucleotide polymorphism. 
Table S2 Quality score of the enrolled studies in the meta-analysis

\begin{tabular}{|c|c|c|c|c|c|c|c|c|c|c|}
\hline Author & Country & $\begin{array}{l}\text { Study } \\
\text { Type }\end{array}$ & Study Period & $\begin{array}{l}\text { Eligibility criteria } \\
\text { of selecting } \\
\text { participants }\end{array}$ & $\begin{array}{l}\text { Appropriate } \\
\text { SLE diagnosis }\end{array}$ & $\begin{array}{l}\text { Described } \\
\text { participants' } \\
\text { characteristics }\end{array}$ & $\begin{array}{l}\text { Ascertainment } \\
\text { of lung cancer }\end{array}$ & $\begin{array}{l}\text { Adjustments } \\
\text { for age and } \\
\text { sex }\end{array}$ & $\begin{array}{l}\text { Other } \\
\text { relevant } \\
\text { adjustments }\end{array}$ & $\begin{array}{l}\text { Quality } \\
\text { Score (0-6) }\end{array}$ \\
\hline Bae et al. (13) & Korea & Cohort & 2008-2014 & Yes & No & Yes & Yes & Yes & Yes & 5 \\
\hline Tallbacka et al. (43) & Finland & Cohort & $1967-1987$ & Yes & Yes & Yes & Yes & No & Yes & 5 \\
\hline Yu et al. (44) & China & Cohort & $1997-2010$ & Yes & No & Yes & Yes & Yes & No & 4 \\
\hline Rees et al. (16) & England & Cohort & 1999-2012 & Yes & No & Yes & Yes & Yes & Yes & 5 \\
\hline Bernatsky et al. (45) & America & Cohort & 1980-1988 & Yes & Yes & Yes & Yes & No & No & 4 \\
\hline Liang et al. (46) & America & Cohort & $1996-2008$ & Yes & No & Yes & Yes & Yes & Yes & 5 \\
\hline Grönhagen et al. (47) & Sweden & Cohort & 1997-2007 & Yes & No & Yes & Yes & Yes & No & 4 \\
\hline Dreyer et al. (48) & Denmark & Cohort & 1991-2005 & Yes & Yes & Yes & Yes & No & No & 4 \\
\hline Parikh-Patel et al. (11) & America & Cohort & 1991-2002 & Yes & Yes & Yes & Yes & Yes & No & 5 \\
\hline Bernatsky et al. (38) & Canada & Cohort & 2005 & Yes & Yes & Yes & Yes & Yes & No & 5 \\
\hline Ragnarsson et al. (49) & Iceland & Cohort & $1957-2001$ & Yes & Yes & Yes & Yes & Yes & No & 5 \\
\hline Sultan et al. (50) & England & Cohort & 1975-1985 & Yes & Yes & Yes & Yes & Yes & No & 5 \\
\hline Cibere et al. (15) & Canada & Cohort & 1978-1999 & Yes & Yes & Yes & Yes & No & Yes & 5 \\
\hline Mellemkjaer et al. (51) & Denmark & Cohort & 1977-1989 & Yes & Yes & Yes & Yes & Yes & Yes & 6 \\
\hline Abu-Shakra et al. (52) & Canada & Cohort & 1978-2002 & Yes & Yes & Yes & Yes & Yes & No & 5 \\
\hline
\end{tabular}




\section{Meta-analysis estimates, given named study is omitted

| Lower Cl Limit OEstimate | Upper Cl Limit

Bae EH (2019)

Tallbacka KR (2018)

Yu K-H (2016)

Rees F (2015)

Bernatsky S (2013)

Liang J-A (2012)

Grönhagen CM (2011)

Dreyer L (2011)

Parikh-Patel A (2008)

Bernatsky S (2005)

Ragnarsson O (2003)

Sultan SM (2000)

Cibere J (2000)

Mellemkjaer L (1997)

Abu-Shakra M (1996)

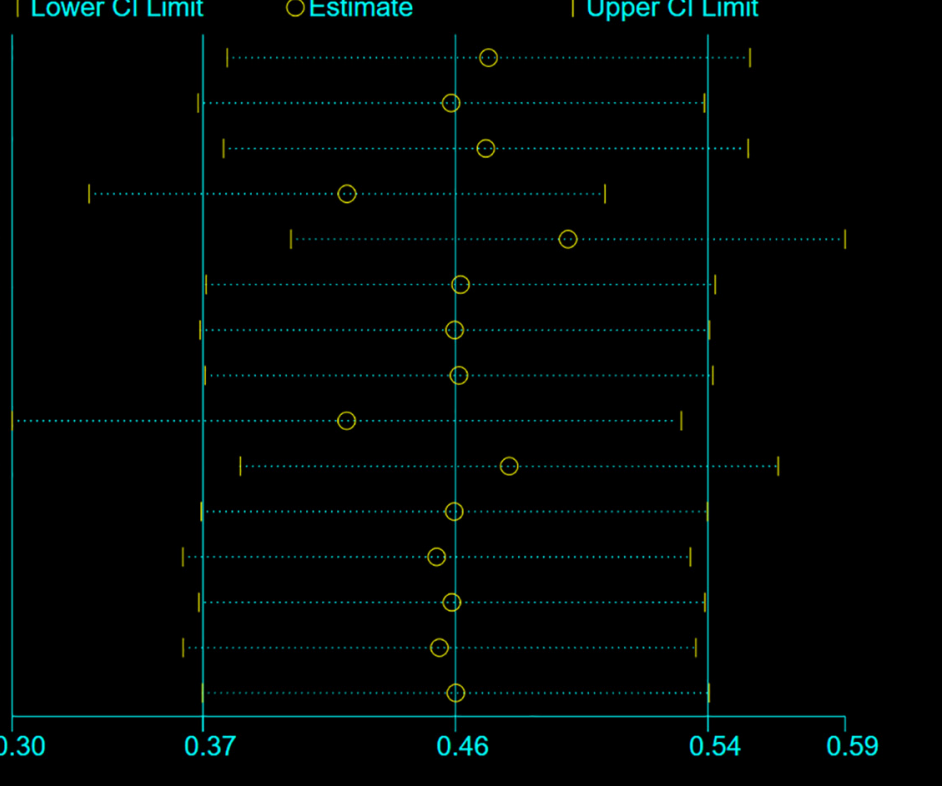

Figure S1 Sensitivity analysis of Meta-analysis.

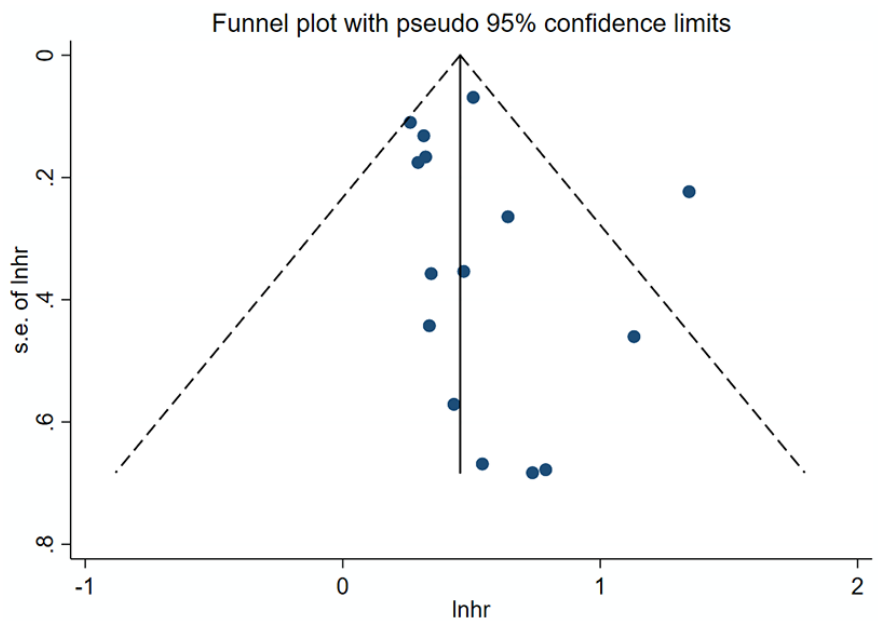

Figure S2 Funnel plot of meta-analysis. 


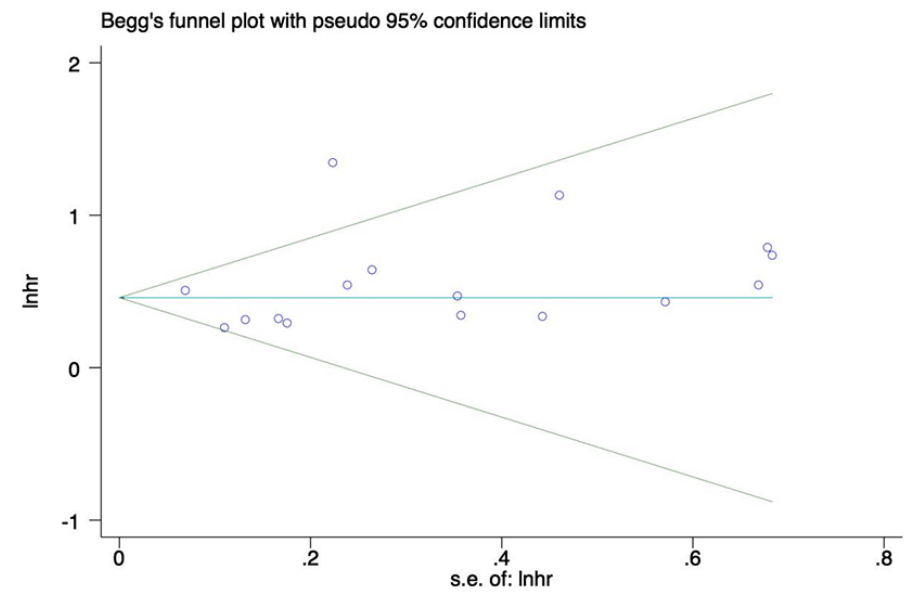

Figure S3 Begg's test of meta-analysis.

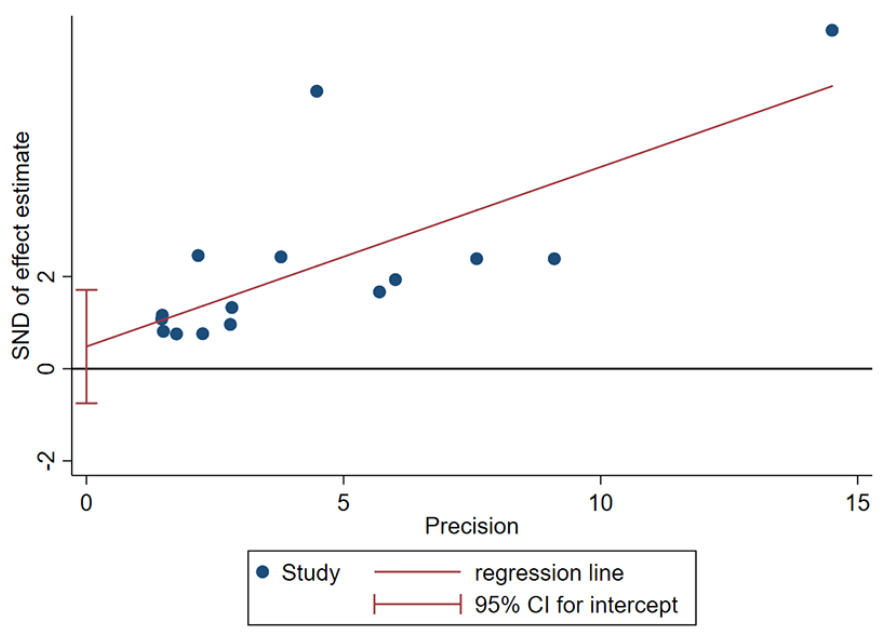

Figure S4 Egger's test of meta-analysis. 


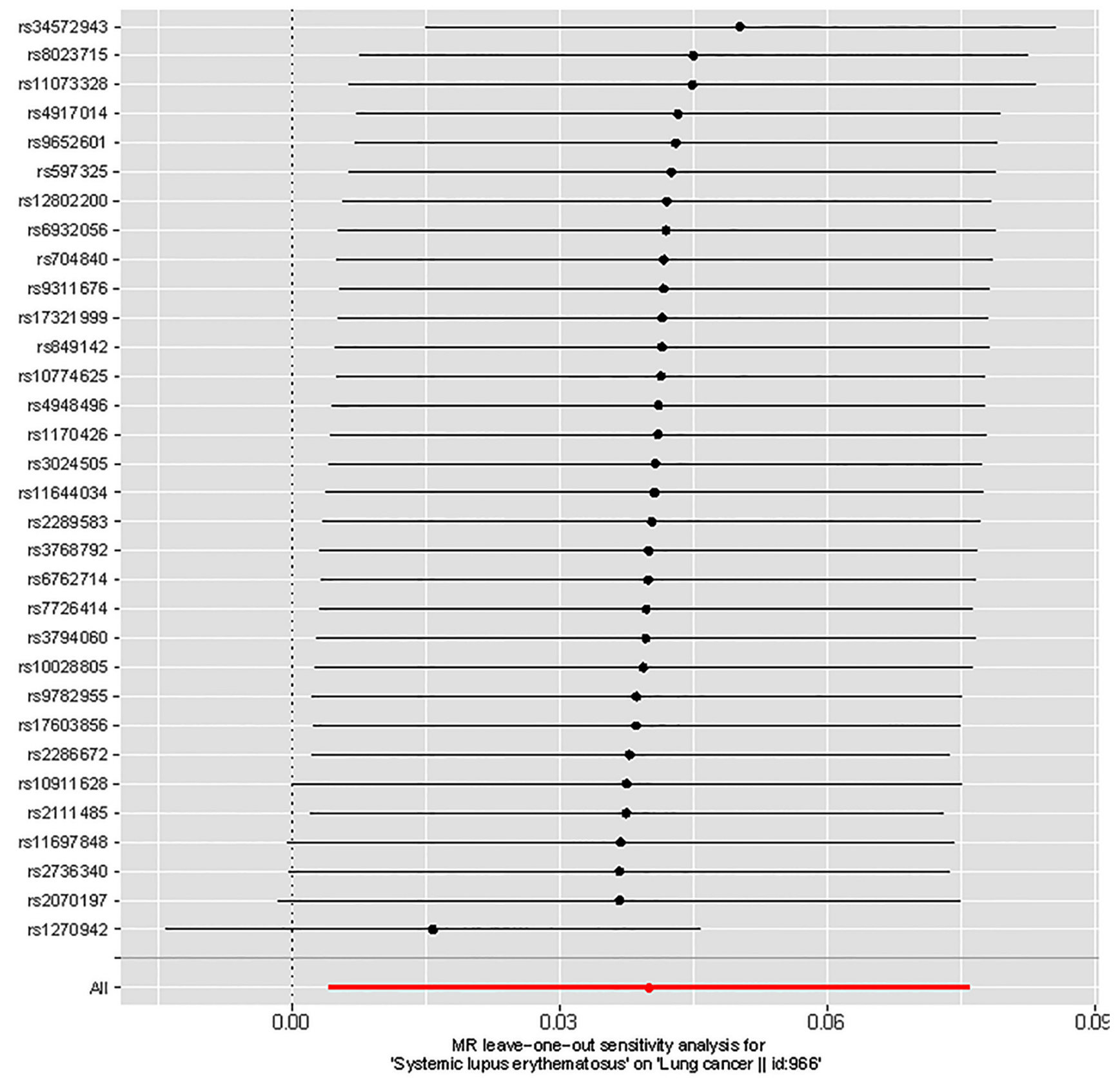

Figure S5 Leave-one-out analysis suggested that no single instrument was strongly driving the overall effect of SLE on lung cancer. SLE, systemic lupus erythematosus. 


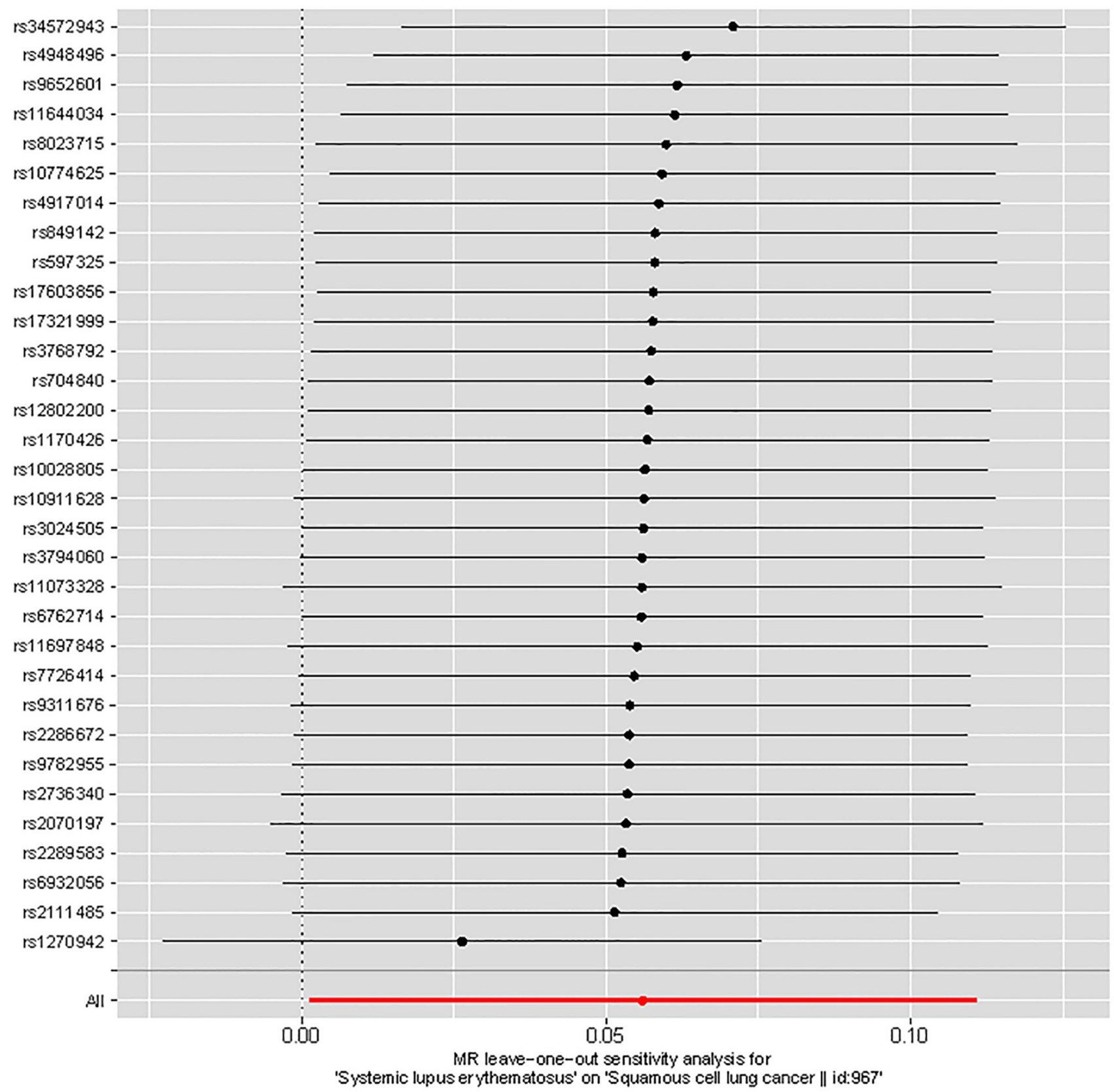

Figure S6 Leave-one-out analysis suggested that no single instrument was strongly driving the overall effect of SLE on squamous cell lung cancer. SLE, systemic lupus erythematosus.

Table S3 MR-Egger pleiotropy test of the associations between SLE and risk of lung cancer with types and sites

\begin{tabular}{lcc}
\hline \multirow{2}{*}{ Outcome } & \multicolumn{2}{c}{ MR-Egger method } \\
\cline { 2 - 3 } & Intercept & P value \\
\hline Lung cancer overall & -0.0120 & 0.16 \\
Type & & 0.45 \\
Lung adenocarcinoma & -0.0092 & 0.11 \\
Squamous cell lung cancer & -0.0210 & \\
\hline
\end{tabular}

SLE, systemic lupus erythematosus. 
Table S4 Association between genetically predisposed systemic lupus erythematosus and potential confounders and mediators

\begin{tabular}{|c|c|c|c|c|c|c|c|c|c|c|c|c|c|c|}
\hline & ID.exposure & ID.outcome & Outcome & Exposure & Method & nsnp & B & SE & $P$ & Lo Cl & $\mathrm{Up} \mathrm{Cl}$ & OR & OR-low 95\% Cl & OR-up 95\% Cl \\
\hline 1 & TG1F34 & ieu-a-90 & Obesity class 1 || ID: ieu-a-90 & $\begin{array}{l}\text { Systemic lupus ery- } \\
\text { thematosus }\end{array}$ & MR Egger & 33 & $1.64 \mathrm{E}-02$ & $2.16 \mathrm{E}-02$ & $4.53 \mathrm{E}-01$ & $-2.59 \mathrm{E}-02$ & $5.87 \mathrm{E}-02$ & $1.02 \mathrm{E}+00$ & $9.74 \mathrm{E}-01$ & $1.06 \mathrm{E}+00$ \\
\hline 2 & TG1F34 & ieu-a-90 & Obesity class 1 || ID: ieu-a-90 & $\begin{array}{l}\text { Systemic lupus ery- } \\
\text { thematosus }\end{array}$ & Weighted median & 33 & 4.11E-03 & $1.37 \mathrm{E}-02$ & 7.64E-01 & $-2.28 \mathrm{E}-02$ & $3.10 \mathrm{E}-02$ & $1.00 \mathrm{E}+00$ & $9.77 \mathrm{E}-01$ & $1.03 \mathrm{E}+00$ \\
\hline 3 & TG1F34 & ieu-a-90 & Obesity class 1 || ID: ieu-a-90 & $\begin{array}{l}\text { Systemic lupus ery- } \\
\text { thematosus }\end{array}$ & $\begin{array}{l}\text { Inverse variance } \\
\text { weighted }\end{array}$ & 33 & $4.84 \mathrm{E}-03$ & $1.20 \mathrm{E}-02$ & $6.86 \mathrm{E}-01$ & $-1.87 \mathrm{E}-02$ & $2.84 \mathrm{E}-02$ & $1.00 \mathrm{E}+00$ & $9.82 \mathrm{E}-01$ & $1.03 \mathrm{E}+00$ \\
\hline 4 & TG1F34 & ieu-a-90 & Obesity class 1 || ID: ieu-a-90 & $\begin{array}{l}\text { Systemic lupus ery- } \\
\text { thematosus }\end{array}$ & Simple mode & 33 & $7.26 \mathrm{E}-03$ & $2.24 \mathrm{E}-02$ & $7.48 \mathrm{E}-01$ & $-3.67 E-02$ & $5.12 \mathrm{E}-02$ & $1.01 \mathrm{E}+00$ & $9.64 \mathrm{E}-01$ & $1.05 \mathrm{E}+00$ \\
\hline 5 & TG1F34 & ieu-a-90 & Obesity class 1 || ID: ieu-a-90 & $\begin{array}{l}\text { Systemic lupus ery- } \\
\text { thematosus }\end{array}$ & Weighted mode & 33 & 5.91E-03 & 1.62E-02 & 7.17E-01 & $-2.58 \mathrm{E}-02$ & 3.77E-02 & $1.01 \mathrm{E}+00$ & $9.74 \mathrm{E}-01$ & $1.04 \mathrm{E}+00$ \\
\hline 6 & TG1F34 & ieu-a-91 & Obesity class 2 || ID: ieu-a-91 & $\begin{array}{l}\text { Systemic lupus ery- } \\
\text { thematosus }\end{array}$ & MR Egger & 33 & $5.17 \mathrm{E}-02$ & $3.19 \mathrm{E}-02$ & 1.15E-01 & $-1.09 \mathrm{E}-02$ & $1.14 \mathrm{E}-01$ & $1.05 \mathrm{E}+00$ & $9.89 \mathrm{E}-01$ & $1.12 \mathrm{E}+00$ \\
\hline 7 & TG1F34 & ieu-a-91 & Obesity class 2 || ID: ieu-a-91 & $\begin{array}{l}\text { Systemic lupus ery- } \\
\text { thematosus }\end{array}$ & Weighted median & 33 & $8.58 \mathrm{E}-03$ & $2.49 \mathrm{E}-02$ & 7.30E-01 & $-4.02 \mathrm{E}-02$ & $5.74 \mathrm{E}-02$ & $1.01 \mathrm{E}+00$ & $9.61 \mathrm{E}-01$ & $1.06 \mathrm{E}+00$ \\
\hline 8 & TG1F34 & ieu-a-91 & Obesity class 2 || ID: ieu-a-91 & $\begin{array}{l}\text { Systemic lupus ery- } \\
\text { thematosus }\end{array}$ & $\begin{array}{l}\text { Inverse variance } \\
\text { weighted }\end{array}$ & 33 & $1.50 \mathrm{E}-02$ & 1.79E-02 & $4.05 \mathrm{E}-01$ & $-2.02 \mathrm{E}-02$ & $5.01 \mathrm{E}-02$ & $1.02 \mathrm{E}+00$ & $9.80 \mathrm{E}-01$ & $1.05 \mathrm{E}+00$ \\
\hline 9 & TG1F34 & ieu-a-91 & Obesity class 2 || ID: ieu-a-91 & $\begin{array}{l}\text { Systemic lupus ery- } \\
\text { thematosus }\end{array}$ & Simple mode & 33 & $7.66 \mathrm{E}-03$ & 4.39E-02 & $8.62 \mathrm{E}-01$ & $-7.84 \mathrm{E}-02$ & $9.37 \mathrm{E}-02$ & $1.01 \mathrm{E}+00$ & $9.25 \mathrm{E}-01$ & $1.10 \mathrm{E}+00$ \\
\hline 10 & TG1F34 & ieu-a-91 & Obesity class 2 || ID: ieu-a-91 & $\begin{array}{l}\text { Systemic lupus ery- } \\
\text { thematosus }\end{array}$ & Weighted mode & 33 & $9.50 \mathrm{E}-03$ & $3.46 \mathrm{E}-02$ & 7.86E-01 & $-5.84 \mathrm{E}-02$ & 7.74E-02 & $1.01 \mathrm{E}+00$ & $9.43 \mathrm{E}-01$ & $1.08 \mathrm{E}+00$ \\
\hline 11 & TG1F34 & ieu-a-92 & Obesity class 3 || ID: ieu-a-92 & $\begin{array}{l}\text { Systemic lupus ery- } \\
\text { thematosus }\end{array}$ & MR Egger & 32 & $1.62 \mathrm{E}-01$ & $6.24 \mathrm{E}-02$ & 1.44E-02 & 3.97E-02 & $2.84 \mathrm{E}-01$ & $1.18 \mathrm{E}+00$ & $1.04 \mathrm{E}+00$ & $1.33 \mathrm{E}+00$ \\
\hline 12 & TG1F34 & ieu-a-92 & Obesity class 3 || ID: ieu-a-92 & $\begin{array}{l}\text { Systemic lupus ery- } \\
\text { thematosus }\end{array}$ & Weighted median & 32 & $1.10 \mathrm{E}-01$ & $4.65 \mathrm{E}-02$ & $1.81 \mathrm{E}-02$ & $1.88 \mathrm{E}-02$ & $2.01 \mathrm{E}-01$ & $1.12 \mathrm{E}+00$ & $1.02 \mathrm{E}+00$ & $1.22 \mathrm{E}+00$ \\
\hline 13 & TG1F34 & ieu-a-92 & Obesity class 3 || ID: ieu-a-92 & $\begin{array}{l}\text { Systemic lupus ery- } \\
\text { thematosus }\end{array}$ & $\begin{array}{l}\text { Inverse variance } \\
\text { weighted }\end{array}$ & 32 & $7.48 \mathrm{E}-02$ & $3.55 \mathrm{E}-02$ & 3.52E-02 & $5.18 \mathrm{E}-03$ & $1.44 \mathrm{E}-01$ & $1.08 \mathrm{E}+00$ & $1.01 \mathrm{E}+00$ & $1.16 \mathrm{E}+00$ \\
\hline 14 & TG1F34 & ieu-a-92 & Obesity class 3 || ID: ieu-a-92 & $\begin{array}{l}\text { Systemic lupus ery- } \\
\text { thematosus }\end{array}$ & Simple mode & 32 & $1.03 E-01$ & 7.97E-02 & $2.06 \mathrm{E}-01$ & $-5.34 \mathrm{E}-02$ & $2.59 \mathrm{E}-01$ & $1.11 \mathrm{E}+00$ & $9.48 \mathrm{E}-01$ & $1.30 \mathrm{E}+00$ \\
\hline 15 & TG1F34 & ieu-a-92 & Obesity class 3 || ID: ieu-a-92 & $\begin{array}{l}\text { Systemic lupus ery- } \\
\text { thematosus }\end{array}$ & Weighted mode & 32 & $1.52 \mathrm{E}-01$ & $6.15 \mathrm{E}-02$ & $1.87 \mathrm{E}-02$ & $3.20 \mathrm{E}-02$ & $2.73 \mathrm{E}-01$ & $1.16 \mathrm{E}+00$ & $1.03 \mathrm{E}+00$ & $1.31 \mathrm{E}+00$ \\
\hline 16 & TG1F34 & ukb-a-224 & $\begin{array}{l}\text { Smoking status: Previous || ID: } \\
\text { ukb-a-224 }\end{array}$ & $\begin{array}{l}\text { Systemic lupus ery- } \\
\text { thematosus }\end{array}$ & MR Egger & 34 & $-2.78 \mathrm{E}-03$ & $2.45 \mathrm{E}-03$ & $2.65 \mathrm{E}-01$ & $-7.59 \mathrm{E}-03$ & $2.03 E-03$ & $9.97 \mathrm{E}-01$ & $9.92 \mathrm{E}-01$ & $1.00 \mathrm{E}+00$ \\
\hline 17 & TG1F34 & ukb-a-224 & $\begin{array}{l}\text { Smoking status: Previous || ID: } \\
\text { ukb-a-224 }\end{array}$ & $\begin{array}{l}\text { Systemic lupus ery- } \\
\text { thematosus }\end{array}$ & Weighted median & 34 & $2.95 \mathrm{E}-04$ & $1.51 \mathrm{E}-03$ & $8.45 \mathrm{E}-01$ & $-2.67 \mathrm{E}-03$ & $3.26 \mathrm{E}-03$ & $1.00 \mathrm{E}+00$ & 9.97E-01 & $1.00 \mathrm{E}+00$ \\
\hline 18 & TG1F34 & ukb-a-224 & $\begin{array}{l}\text { Smoking status: Previous || ID: } \\
\text { ukb-a-224 }\end{array}$ & $\begin{array}{l}\text { Systemic lupus ery- } \\
\text { thematosus }\end{array}$ & $\begin{array}{l}\text { Inverse variance } \\
\text { weighted }\end{array}$ & 34 & $-7.76 \mathrm{E}-04$ & $1.42 \mathrm{E}-03$ & $5.84 \mathrm{E}-01$ & $-3.55 \mathrm{E}-03$ & $2.00 \mathrm{E}-03$ & $9.99 \mathrm{E}-01$ & $9.96 \mathrm{E}-01$ & $1.00 \mathrm{E}+00$ \\
\hline 19 & TG1F34 & ukb-a-224 & $\begin{array}{l}\text { Smoking status: Previous || ID: } \\
\text { ukb-a-224 }\end{array}$ & $\begin{array}{l}\text { Systemic lupus ery- } \\
\text { thematosus }\end{array}$ & Simple mode & 34 & $1.67 \mathrm{E}-03$ & $2.80 \mathrm{E}-03$ & $5.56 \mathrm{E}-01$ & $-3.82 \mathrm{E}-03$ & $7.15 \mathrm{E}-03$ & $1.00 \mathrm{E}+00$ & 9.96E-01 & $1.01 \mathrm{E}+00$ \\
\hline 20 & TG1F34 & ukb-a-224 & $\begin{array}{l}\text { Smoking status: Previous || ID: } \\
\text { ukb-a-224 }\end{array}$ & $\begin{array}{l}\text { Systemic lupus ery- } \\
\text { thematosus }\end{array}$ & Weighted mode & 34 & $1.46 \mathrm{E}-03$ & $2.11 \mathrm{E}-03$ & 4.95E-01 & $-2.68 \mathrm{E}-03$ & $5.59 \mathrm{E}-03$ & $1.00 \mathrm{E}+00$ & $9.97 \mathrm{E}-01$ & $1.01 \mathrm{E}+00$ \\
\hline 21 & TG1F34 & ukb-a-225 & $\begin{array}{l}\text { Smoking status: Current || ID: } \\
\text { ukb-a-225 }\end{array}$ & $\begin{array}{l}\text { Systemic lupus ery- } \\
\text { thematosus }\end{array}$ & MR Egger & 34 & $-1.80 \mathrm{E}-03$ & $1.20 \mathrm{E}-03$ & $1.44 \mathrm{E}-01$ & $-4.16 \mathrm{E}-03$ & $5.57 \mathrm{E}-04$ & $9.98 \mathrm{E}-01$ & $9.96 \mathrm{E}-01$ & $1.00 \mathrm{E}+00$ \\
\hline 22 & TG1F34 & ukb-a-225 & $\begin{array}{l}\text { Smoking status: Current || ID: } \\
\text { ukb-a-225 }\end{array}$ & $\begin{array}{l}\text { Systemic lupus ery- } \\
\text { thematosus }\end{array}$ & Weighted median & 34 & $-9.66 \mathrm{E}-04$ & 8.38E-04 & $2.49 \mathrm{E}-01$ & $-2.61 \mathrm{E}-03$ & $6.77 \mathrm{E}-04$ & $9.99 \mathrm{E}-01$ & 9.97E-01 & $1.00 \mathrm{E}+00$ \\
\hline 23 & TG1F34 & ukb-a-225 & $\begin{array}{l}\text { Smoking status: Current || ID: } \\
\text { ukb-a-225 }\end{array}$ & $\begin{array}{l}\text { Systemic lupus ery- } \\
\text { thematosus }\end{array}$ & $\begin{array}{l}\text { Inverse variance } \\
\text { weighted }\end{array}$ & 34 & $-1.04 \mathrm{E}-03$ & $6.90 \mathrm{E}-04$ & $1.31 \mathrm{E}-01$ & $-2.39 \mathrm{E}-03$ & $3.11 \mathrm{E}-04$ & $9.99 \mathrm{E}-01$ & $9.98 \mathrm{E}-01$ & $1.00 \mathrm{E}+00$ \\
\hline 24 & TG1F34 & ukb-a-225 & $\begin{array}{l}\text { Smoking status: Current || ID: } \\
\text { ukb-a-225 }\end{array}$ & $\begin{array}{l}\text { Systemic lupus ery- } \\
\text { thematosus }\end{array}$ & Simple mode & 34 & $4.25 \mathrm{E}-06$ & $1.55 \mathrm{E}-03$ & $9.98 \mathrm{E}-01$ & $-3.03 E-03$ & $3.04 \mathrm{E}-03$ & $1.00 \mathrm{E}+00$ & $9.97 \mathrm{E}-01$ & $1.00 \mathrm{E}+00$ \\
\hline 25 & TG1F34 & ukb-a-225 & $\begin{array}{l}\text { Smoking status: Current || ID: } \\
\text { ukb-a-225 }\end{array}$ & $\begin{array}{l}\text { Systemic lupus ery- } \\
\text { thematosus }\end{array}$ & Weighted mode & 34 & $-1.11 \mathrm{E}-03$ & $9.51 \mathrm{E}-04$ & $2.50 \mathrm{E}-01$ & $-2.98 \mathrm{E}-03$ & 7.51E-04 & $9.99 \mathrm{E}-01$ & $9.97 \mathrm{E}-01$ & $1.00 \mathrm{E}+00$ \\
\hline 26 & TG1F34 & ukb-a-227 & $\begin{array}{l}\text { Alcohol drinker status: Previ- } \\
\text { ous || ID: ukb-a-227 }\end{array}$ & $\begin{array}{l}\text { Systemic lupus ery- } \\
\text { thematosus }\end{array}$ & MR Egger & 34 & $2.36 \mathrm{E}-04$ & $5.79 \mathrm{E}-04$ & $6.87 \mathrm{E}-01$ & $-8.99 \mathrm{E}-04$ & 1.37E-03 & $1.00 \mathrm{E}+00$ & $9.99 \mathrm{E}-01$ & $1.00 \mathrm{E}+00$ \\
\hline 27 & TG1F34 & ukb-a-227 & $\begin{array}{l}\text { Alcohol drinker status: Previ- } \\
\text { ous || ID: ukb-a-227 }\end{array}$ & $\begin{array}{l}\text { Systemic lupus ery- } \\
\text { thematosus }\end{array}$ & Weighted median & 34 & $4.84 \mathrm{E}-04$ & $4.64 \mathrm{E}-04$ & 2.97E-01 & $-4.26 \mathrm{E}-04$ & $1.39 \mathrm{E}-03$ & $1.00 \mathrm{E}+00$ & $1.00 \mathrm{E}+00$ & $1.00 \mathrm{E}+00$ \\
\hline 28 & TG1F34 & ukb-a-227 & $\begin{array}{l}\text { Alcohol drinker status: Previ- } \\
\text { ous || ID: ukb-a-227 }\end{array}$ & $\begin{array}{l}\text { Systemic lupus ery- } \\
\text { thematosus }\end{array}$ & $\begin{array}{l}\text { Inverse variance } \\
\text { weighted }\end{array}$ & 34 & $2.47 \mathrm{E}-04$ & 3.34E-04 & 4.59E-01 & $-4.08 \mathrm{E}-04$ & $9.02 \mathrm{E}-04$ & $1.00 \mathrm{E}+00$ & $1.00 \mathrm{E}+00$ & $1.00 \mathrm{E}+00$ \\
\hline 29 & TG1F34 & ukb-a-227 & $\begin{array}{l}\text { Alcohol drinker status: Previ- } \\
\text { ous || ID: ukb-a-227 }\end{array}$ & $\begin{array}{l}\text { Systemic lupus ery- } \\
\text { thematosus }\end{array}$ & Simple mode & 34 & $2.28 \mathrm{E}-04$ & 7.53E-04 & 7.64E-01 & $-1.25 \mathrm{E}-03$ & $1.70 \mathrm{E}-03$ & $1.00 \mathrm{E}+00$ & $9.99 \mathrm{E}-01$ & $1.00 \mathrm{E}+00$ \\
\hline 30 & TG1F34 & ukb-a-227 & $\begin{array}{l}\text { Alcohol drinker status: Previ- } \\
\text { ous || ID: ukb-a-227 }\end{array}$ & $\begin{array}{l}\text { Systemic lupus ery- } \\
\text { thematosus }\end{array}$ & Weighted mode & 34 & $4.41 \mathrm{E}-04$ & 4.93E-04 & 3.78E-01 & $-5.26 \mathrm{E}-04$ & $1.41 \mathrm{E}-03$ & $1.00 \mathrm{E}+00$ & 9.99E-01 & $1.00 \mathrm{E}+00$ \\
\hline
\end{tabular}

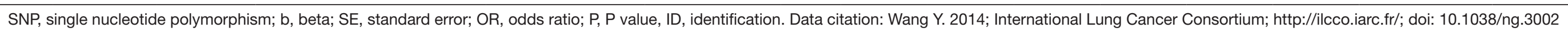

